\title{
Determination of the effective thickness of a porous electrode in a flow-through reactor; effect of the specific surface area of stainless steel fibres, used as a porous cathode, during the deposition of $\mathrm{Ag}(\mathrm{I})$ ions
}

\author{
J.L. Nava ${ }^{\mathrm{a}, *}$, M.T. Oropeza ${ }^{\mathrm{b}}$, C. Ponce de León ${ }^{\mathrm{c}}$, J. González-García ${ }^{\mathrm{d}}$, A.J. Frías-Ferrer ${ }^{\mathrm{d}}$ \\ ${ }^{a}$ Universidad Autónoma Metropolitana-Iztapalapa, Departamento de Química, 55-534, C.P. 09340, México D.F., Mexico \\ ${ }^{\mathrm{b}}$ Centro de Graduados e Investigación del Instituto Tecnológico de Tijuana, Blvd. Industrial s/n, CP 22500, Tijuana B.C., Mexico \\ c Electrochemical Engineering Group, Research Institute for Industry, (RIFI), Materials Engineering Group, School of Engineering Sciences, \\ University of Southampton, University Road Highfield, Southampton, SO17 IBJ, United Kingdom \\ ${ }^{\mathrm{d}}$ Universidad de Alicante, Departamento de Química Física e Instituto de Electroquímica, Ap. de orreos 99.03080, Alicante, Spain
}

Received 13 October 2006; received in revised form 22 September 2007; accepted 1 December 2007

\section{Abstract}

This study discusses the use of potential distribution analysis during the deposition of metal ions, at limiting current conditions and determines the optimum electrode thickness at which no hydrogen evolution occurs. The potential distribution studies were carried out on stainless-steel fibres of three different surface areas. The fibres were used as cathodic porous electrodes during the deposition of $\mathrm{Ag}(\mathrm{I})$ ions contained in $0.1 \mathrm{~mol} \mathrm{dm}^{-3}$ $\mathrm{KNO}_{3}$ and $0.6 \mathrm{~mol} \mathrm{dm}^{-3} \mathrm{NH}_{4} \mathrm{OH}$ electrolyte. The comparison between the experimental and the theoretical potential distributions show good agreement at mean linear flow rates in the range of 0.24 and $0.94 \mathrm{~cm} \mathrm{~s}^{-1}$.

(C) 2007 Elsevier B.V. All rights reserved.

Keywords: Electrode thickness; Flow-through; Fixed bed electrode reactor; Packed bed electrode; Potential distribution; Potential drop; silver ion

\section{Introduction}

Packed bed electrodes can be used for electrochemical recovery of heavy metals from a variety of industrial and laboratory model solutions (Bennion and Newman, 1972; Doherty et al., 1996; El-Deab et al., 1999; Gaunand et al., 1977; Lanza and Bertazzoli, 2000; Matloz and Newman, 1986; Podlaha and Fenton, 1995; Ponce de León and Pletcher, 1996; Saleh, 2004; Soltan et al., 2003; Trainham and Newman, 1977). The packed bed electrode forms a porous flow-through configuration providing large surface area usually depleting the concentration of metal ions below $0.1 \mathrm{ppm}$.

Some studies have reported that flow-through configurations suffer from non-uniform potential and current distribution (Bennion and Newman, 1972; Doherty et al., 1996; El-Deab

\footnotetext{
* Corresponding author. Tel.: +52 555804 4600x2685; fax: +52 555804 4666.

E-mail address: jlnm@xanum.uam.mx (J.L. Nava).
}

et al., 1999; Gaunand et al., 1977; Matloz and Newman, 1986; 37 Saleh, 2004; Sioda, 1971; Trainham and Newman, 1977). 38 Newman et al. in 1962 demonstrated this problem when Tafel 39 kinetic was coupled with significant solid phase (electrode 40 material) and electrolyte resistivity. In another paper related to 41 the potential and current distribution, Bennion and Newman 42 (1972) used the deposition of copper ions on carbon flakes to 43 study the design principles of flow-through porous electrodes. 44 The authors concluded that flow rate and bed thickness deter- 45 mine the ohmic potential drop within the porous electrode. 46 Another conclusion was that the potential difference between 47 the carbon matrix and the solution at all points within the porous 48 electrode should be sufficient, but not too large to ensure de- 49 position without hydrogen evolution. Sabacky and Evans 50 (1979) used a fluidised copper particles cathode for copper 51 recovery and reported that the efficiency and power consump- 52 tion depended on copper and acid concentration, particle size, 53 resistivity of the electrolyte and superficial current density. 54 Their model predicted inefficient utilization of the bed surface 55 


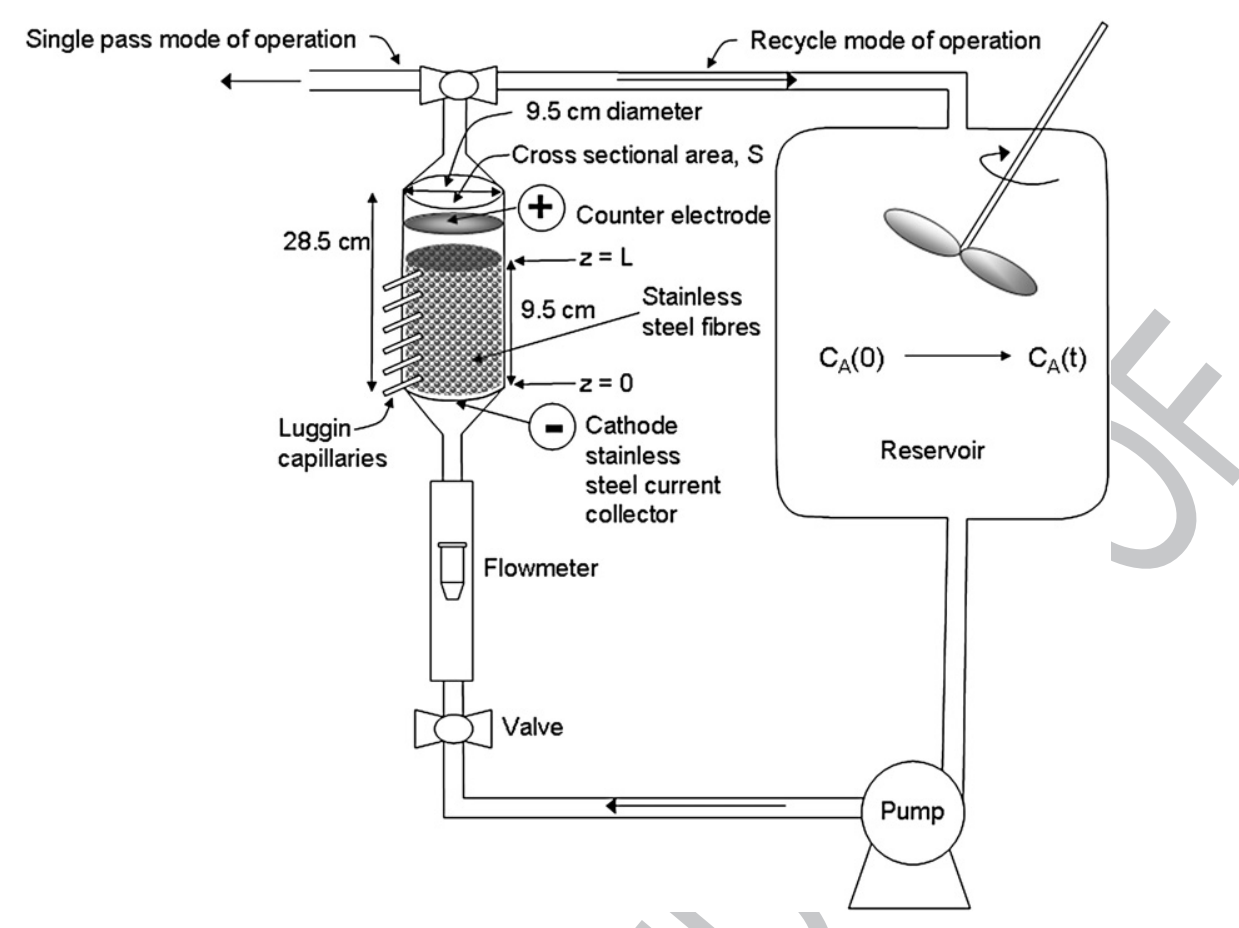

Fig. 1. Experimental flow circuit and packed bed electrochemical reactor.

area at high values of electrode and electrolyte resistivity and introduced the effectiveness factor to compare maximum and actual limiting currents. The influence of electrolyte and electrode resistivity turned to be small when compared with the bed resistivity originated by the bed expansion caused by hydrogen bubbles at high cathode voltages. In a more recent paper, Saleh in 2004 re-introduced the concept of effectiveness factor as the ratio between the total obtainable limiting current and the maximum limiting current in absence of ohmic drop. The study was based on the deposition of zinc in alkaline solution where the hydrogen evolution reaction and the deposition of zinc take place at similar potential. Saleh concluded that hydrogen evolution accentuates the ohmic effect. Similarly, Like and Langer in 1991 discussed the internal ohmic limits in a flow-through porous electrode using Tafel kinetics. They showed that during the electrolyses, thinner electrodes help to maximize the current density.

The aim of this paper is to use a potential distribution analysis to estimate the optimum length of a packed bed electrode reactor during a metal recovery process avoiding secondary reactions such as the hydrogen evolution. This is shown by taking the deposition of $\operatorname{Ag}(\mathrm{I})$ ions on three stainless steel fibres porous cathodes of different specific surface areas. The potential region for the reduction of $\operatorname{Ag}(\mathrm{I})$ ions at mass transport controlled conditions was determined by rotating disc electrode experiments (RDE). A potential value in this region was then selected for the electrolysis experiments in a flow cell. Mass transport characterization of the three stainless steel fibres porous electrodes was used to obtain the parameters included into the one-dimension potential distribution model. The theoretical potential distribution calculations were compared with the experimental data.
2. Mass balance in a recirculating flow-through reactor 88 with 3D electrode

The concentration profile of the electroactive species in a 90 flow-through reactor in batch recycle mode of operation (see 91 Fig. 1), neglecting phase changes and dispersion effects in the 92 porous electrode, can be described by the following equation 93 (Fahidy, 1985):

$\frac{C(t)}{C(t=0)}=\exp -\left[\frac{t}{\tau_{T}}\left(1-\exp ^{-[\alpha L]}\right)\right]$

where $C(t)$ and $C(t=0)$ are the concentration of the electroactive 96 species during the electrolysis at time $t$ and 0 respectively, $\tau_{T}$ is 97 the mean residence time of the electrolyte in the reservoir 98 defined as $\tau_{T}=V_{T} / Q$, where $V_{T}$ and $Q$ are the volume of the 99 reservoir and the volumetric flow rate. $L$ is the length of the 100 porous electrode and $\alpha$ is the following group parameter:

$\alpha=\frac{k_{m} a(1-\varepsilon)}{u}$

where $k_{m}$ is the average mass transport coefficient assuming that 103 it is independent of the axial position $(z), a$, is the specific 104 surface electrode area, is the electrode porosity and $u$ is the 105 mean linear flow velocity of the electrolyte.

\section{Potential distribution in a single pass flow-through reactor 107 with 3D electrode

The unidirectional potential distribution in electrically con- 109 ductive porous electrodes under limiting current conditions can 110 
t1.1 Table 1

Physical properties of the three stainless-steel fibres porous electrode of $2.9 \mathrm{~g} \mathrm{~cm}^{-3}$ density contained in reactor of $71 \mathrm{~cm}^{-2}$ cross sectional area and $9.5 \mathrm{~cm}$ long

\begin{tabular}{|c|c|c|}
\hline Specific surface area* & Porosity & Electrode area per gram \\
\hline$a / \mathrm{cm}^{-1}$ & $/ \varepsilon$ & $/ \mathrm{cm}^{2} \mathrm{~g}^{-1}$ \\
\hline 193 & 0.969 & 66 \\
\hline 107 & 0.910 & 37 \\
\hline 81 & 0.907 & 286 \\
\hline
\end{tabular}

*The specific surface area of the porous electrode, a, (geometric area of the electrode/volume occupied by the electrode) was calculated by multiplication of the electrode area per gram by the electrode density.

be modelled by assuming plug-flow conditions and neglecting conductivity changes of the electrolyte during electrolysis due to an excess of supporting electrolyte. The model assumes that only the concentration decay of the electroactive species within the electrode is responsible for the potential distribution (Fahidy, 1985):

$\varphi_{e}(z)-\varphi_{e}(z=0)=-\frac{\mathrm{nFuC}(z=0)}{\alpha \sigma_{e}}\left[\alpha z+\exp ^{-\alpha z}-1\right]$

where $\varphi_{e}(z)$ is the potential of the electrolyte at any position within the interstitial spaces of the electrode, $\varphi_{\mathrm{e}}(z=0)$ is the potential at the inlet of the electrode, $\mathrm{n}$ is the number of electrons transferred, $F$ the Faraday constant, $C(z=0)$ is the concentration of the electroactive species at the inlet of the porous electrode, and $\sigma_{e}$ is the conductivity of the electrolyte in the interstitial space of the porous electrode given by (Fahidy, 1985):

$\sigma_{e}=\sigma \frac{2 \varepsilon}{(3-\varepsilon)}$

\section{where $\sigma$ is the conductivity of the electrolyte.}

\section{Experimental}

\subsection{Equipment and solutions}

The electrolyte consisted of $4.6 \times 10^{-3} \mathrm{~mol} \mathrm{dm}^{-3} \mathrm{AgNO}_{3}, 0.1 \mathrm{~mol}$ $\mathrm{dm}^{-3} \mathrm{KNO}_{3}$ and $0.6 \mathrm{~mol} \mathrm{dm}{ }^{-3} \mathrm{NH}_{4} \mathrm{OH}$ (Oropeza et al., 1995) and was prepared using analytical grade reactants dissolved in deionised water

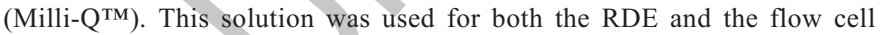
experiments. In the flow cell, $5 \mathrm{~L}$ of this solution were circulated through the electrolyte circuit (Fig. 1). A potentiostat-galvanostat PARTM Model 273A was used to apply and control the potential of both the RDE and the stainless steel porous electrodes. All potentials are referred to the standard hydrogen electrode, SHE. The solutions were deoxygenated during approximately $10 \mathrm{~min}$ and the experiments were carried out under a nitrogen atmosphere at $25 \pm 3{ }^{\circ} \mathrm{C}$.

\subsection{Electrochemical cells}

\subsubsection{Experiments at the rotating disc electrode (RDE) cell}

A three glass electrode electrochemical cell of $100 \mathrm{~mL}$ capacity with nitrogen inlet was used. A Tacussel ${ }^{\mathrm{TM}}$ rotating disk electrode assembly model F69100 was used with this cell. The working electrode was stainless steel disk of $0.0314 \mathrm{~cm}^{-2}$ and the reference and counter electrodes were saturated sulphate
(SSE) (Tacussel ${ }^{\mathrm{TM}}$ model XR200) and a graphite bar, respectively. The working 147 electrode was polished with $0.3 \mu \mathrm{m}$ alumina powder followed by $5 \mathrm{~min}$ of 148 ultrasonic bath and a final rinse with distilled water before each experiment. 149 The ultrasonic bath helps to remove the traces of alumina left on the electrode 150 surface.

\subsubsection{Experiments in the packed bed flow cell}

Fig. 1 shows a schematic diagram of the packed bed flow cell; the body of 153 the reactor consists of a propylene tube of $28.5 \mathrm{~cm}$ length and $9.5 \mathrm{~cm}$ internal 154 diameter. The tube was fitted with flanges at both ends. Two Nylon cones with a 155 flange were attached at the top and bottom of the tube using the flanges in order 156 to form the inlet and outlet of the reactor. The conical shape improves the 157 distribution of the fluid at the inlet and avoids back mixing of the electrolyte at 158 the exit. The polypropylene tube contained stainless steel 304 fibres as a cathode 159 electrode. Three different specific surface area fibres supported by a stainless 160 steel mesh current collector of $9.4 \mathrm{~cm}$ diameter were used separately as porous 161 electrodes. The fibres were obtained by changing the distance between the 162 cutting tool and a stainless steel rod mounted on a lathe. The specific area of the 163 packed bed electrode was calculated by multiplying the electrode area per gram 164 $\left(\mathrm{cm}^{2} \mathrm{~g}^{-1}\right)$ by its density; Table 1 shows the parameters of this material. Small 165 plastic tubes inserted on $3 \mathrm{~mm}$ holes drilled along the propylene tube length 166 were used as Luggin capillaries to monitor the local potential of the solution 167 throughout the packed bed electrode (see Fig. 1). A titanium mesh covered with 168 a layer of $\mathrm{RuO}_{2}$ was used as counter electrode at the top of the reactor. 169

A March MFG pump of $1 / 25 \mathrm{hp}$ was used to recirculate the electrolyte through 170 the reactor and the flow rates were measured using a variable area polycarbonate 171 flowmeter (Cole Palmer model F44376LH-8). The electrolyte flow circuit was 172 constructed with Master Flex tubing, (C-Flex 6424-16, 0.5 in. diameter). All the 173 valves and three way connectors were assembled with PVC materials. The 174 electrolyte was contained in a 5 litre reservoir fitted with a stainless-steel stirrer 175 powered by a $115 \mathrm{~V}$ Caframo ${ }^{\mathrm{TM}}$ electric motor of variable velocity used to achieve 176 well mixed conditions. The electrolyte circuit was designed to allow single pass or 177 recirculation modes of operation.

During electrolysis, the concentration of silver ions was potentiometrically 179 determined using an ion selective electrode (ISE) model 9616N from Orion 180 Research Inc. ${ }^{\mathrm{TM}}$. The electrode was calibrated each time a new sets of samples 181 from a different experiment were taken and was allowed to equilibrate with 182 solutions of similar concentration of $\mathrm{Ag}(\mathrm{I})$ ions expected from the samples. The 183 potential of the electrolyte along the packed bed working electrode was 184 monitored with a saturated sulphate reference electrode SSE $(E=615 \mathrm{mV} v s .185$ SHE), connected to the Luggin capillaries.

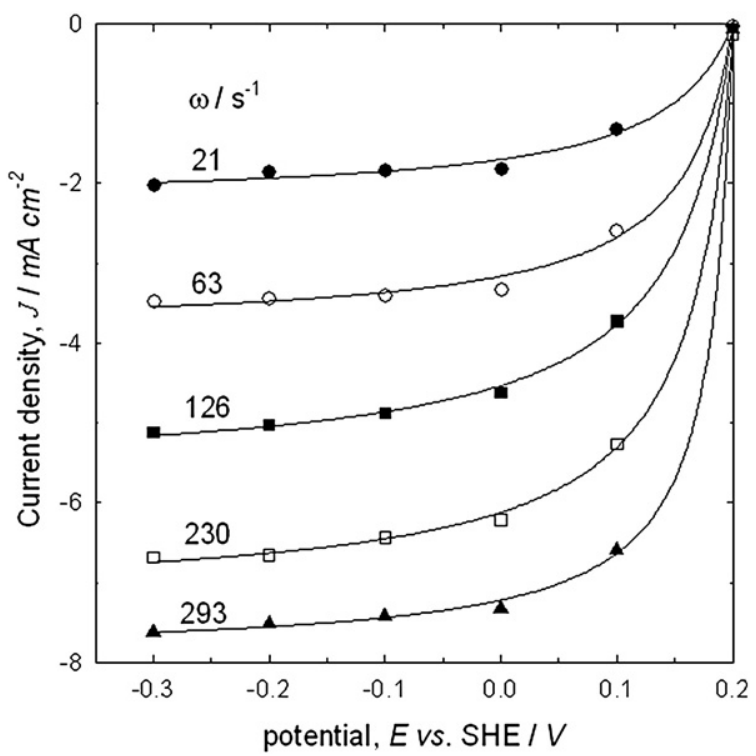

Fig. 2. Current density vs. potential curves for $\operatorname{Ag}(\mathrm{I})$ ions deposition process. Electrolyte: $4.6 \times 10^{-3} \mathrm{~mol} \mathrm{dm}^{-3} \mathrm{AgNO}_{3}$ in $0.1 \mathrm{~mol} \mathrm{dm}^{-3} \mathrm{KNO}_{3}$ and $0.6 \mathrm{~mol} \mathrm{dm}^{-3}$ $\mathrm{NH}_{4} \mathrm{OH}$. 


\section{Analysis of results and discussion}

\subsection{Determination of electrolysis potential for $\mathrm{Ag}(I) / \mathrm{Ag}(0)$ reduction process}

Current $v s$. time curves were recorded with different potential steps applied to the stainless steel rotating disc electrode. The potential steps were from the open circuit potential (OCP) at $0.2 \mathrm{~V} v s$. SHE to 0.1, 0.0, $-0.1,-0.2$ and $-0.3 \mathrm{~V} v$ s. SHE each at different angular velocities. The deposited silver was stripped off from the electrode by applying a positive potential of $0.35 v s$. SHE after each chronoamperometric experiment, followed by the polishing procedure outlined in the experimental section. These chronoamperometric plots were used to construct the current density $v s$. potential curves for $\operatorname{Ag}(\mathrm{I})$ ion deposition taking the current at time $t$, of $6 \mathrm{~s}$ after the potential step was applied. Fig. 2 shows the current density vs. potential curves obtained from the chronoamperometric experiments at different angular velocities and shows that metallic silver deposition starts at less than $0.2 \mathrm{~V} v s$. SHE for all rotation rates with the limiting current plateau between $0.0 \mathrm{~V}$ and $-0.3 \mathrm{~V} v$ s. SHE. Although not shown in the Figure it was observed that hydrogen evolution started at $<-0.3 \mathrm{~V} v \mathrm{~s}$. SHE.

The RDE experiments established that silver ion deposition was mass transport controlled between $0.0 \mathrm{~V}$ and $-0.3 \mathrm{~V} v s$. SHE. It is important to point out that even when the limiting current plateau started slightly positive to $0 \mathrm{~V} v s$. SHE in the RDE for all angular velocities (see Fig. 2) the potential value used for the electrolysis in the flowthrough electrode was $+0.1 \mathrm{~V} v s$. SHE applied at $z=0$ (see Fig. 1). The assumption is that at such potential the process is still mass transport controlled in the packed bed electrode system.

\subsection{Mass transport characterization in the packed bed electrode.}

The mass transport coefficients were determined by electrolysis of $\mathrm{Ag}(\mathrm{I})$ ion solutions in the packed bed flow-through reactor in recycle mode of operation (Fig. 1). The electrolysis were carried out by applying $+0.1 \mathrm{~V} v s$. SHE on the current collector, at $z=0$, situated at the inlet of the packed bed electrode reactor. Since it is unlikely that the RDE and the packed bed cell developed the same mass transport,

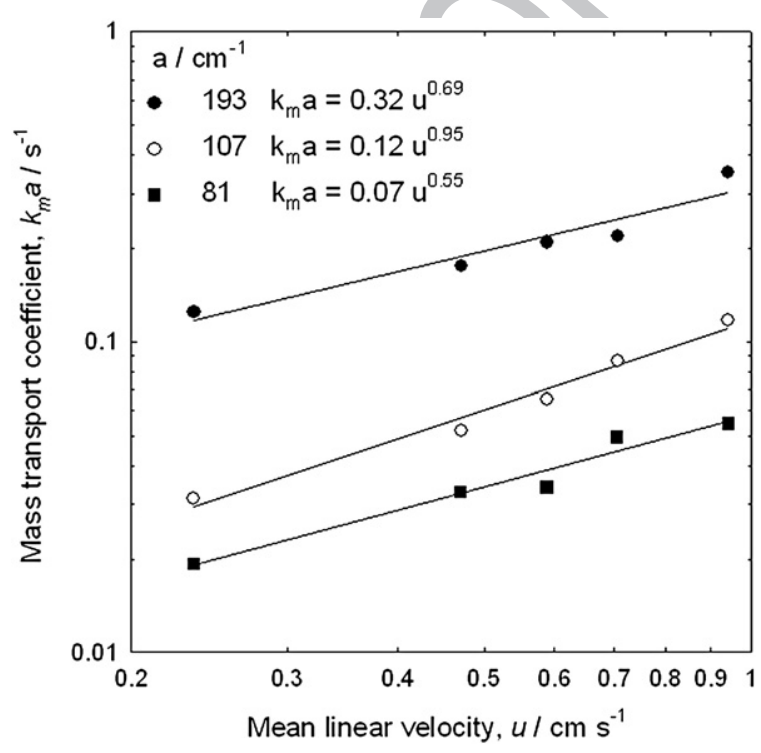

Fig. 3. Mass transport coefficients $v s$. mean linear flow electrolyte velocity for the reduction of $\mathrm{Ag}(\mathrm{I})$ ions. Specific areas of stainless-steel fibres: 81, 107 and $193 \mathrm{~cm}^{-1}$. Potential of the electrolysis at $z=0: 0.1 \mathrm{~V} v s$. SHE.
Table 2

Properties and parameters used to model the potential distribution throughout the packed bed electrode

Concentration of $\operatorname{Ag}(\mathrm{I})$ at the entrance of porous electrode

\begin{tabular}{llll}
$C(z=0) / \mathrm{mol} \mathrm{cm}^{-3}$ & $\frac{\text { conductivity }}{\sigma / \Omega^{-1} \mathrm{~cm}^{-1}}$ & $n$ & $\mathrm{t} 2.4$ \\
$\mathrm{X} 10^{6}$ & & & $\mathrm{t} 2.5$ \\
\hline 4.6 & 0.100 & 1 & $\mathrm{t} 2.6$ \\
\hline
\end{tabular}

the selection of the electrolysis potential was based on the fact that the 221 average mass transport in the packed bed electrode is lower than in the 222 rotating disc electrode. The calculation of the mass transport coefficient 223 in the RDE and in the packed bed systems was $9 \times 10^{-3} \mathrm{~cm} \mathrm{~s}^{-1}$ and 224 $7 \times 10^{-4} \mathrm{~cm} \mathrm{~s}^{-1}$ respectively, showing that $\mathrm{k}_{\mathrm{m}}$ is approximately one 225 order of magnitude larger in the RDE cell. This justifies the selection 226 of $+0.1 \mathrm{~V} v s$. $\mathrm{AgCl}$ for mass transport controlled electrolysis in the 227 packed bed electrode. The mean linear flow velocities, $\mathrm{u}$, during the 228 electrolysis, were between 0.23 and $0.94 \mathrm{~cm} \mathrm{~s}^{-1}$.

Fig. 3 shows the mean mass transport coefficients multiplied by the 230 electrode area $k_{m} a, v s$. the mean linear flow velocity $u$, for the three 231 packed bed electrodes. These values were obtained from the slopes of 232 the curves of concentration decay vs. time during the electrolysis of $\mathrm{Ag} 233$ (I) ions and applying the Eq. (1). The mass transport coefficients 234 increased with the specific surface area of each electrode and with the 235 mean linear flow velocity of the electrolyte. From the correlations 236 $k_{m} a=\mathrm{bu}^{\mathrm{c}}$ showed in the plots, it can be observed that in the three 237 electrodes of different specific surface area, the value of the velocity 238 exponent, c, falls between 0.55 and 0.95 , indicating that the flow 239 pattern is a complex function of the specific surface area, electrode 240 porosity and shape of the fibres (Delanghe et al., 1990; Langlois and 241 Coeuret, 1989). On the other hand, the values of the coefficient b, 242 associated with the electrode geometry, increased with the specific 243 surface area showing the interdependence of this parameter in the mass 244 transport correlation. It is important to mention that the exact form of 245

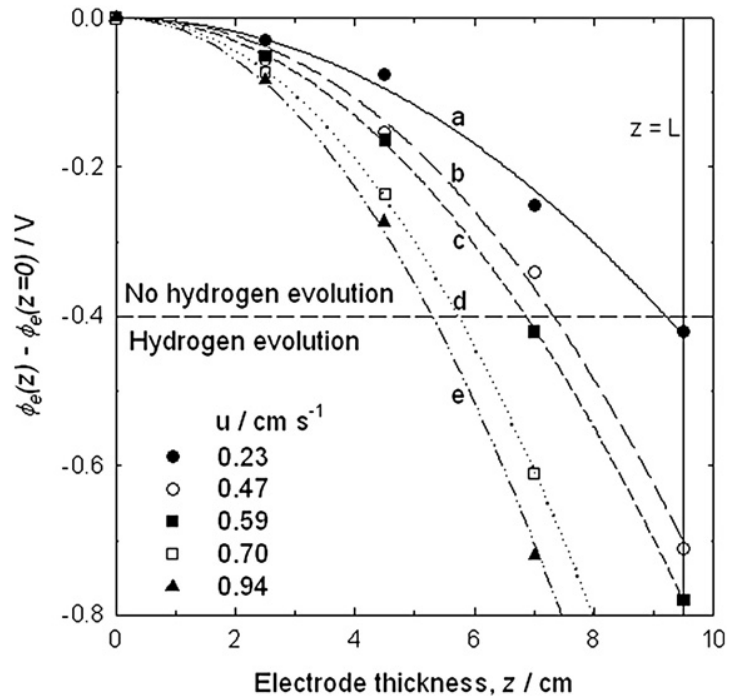

Fig. 4. Comparison between experimental and theoretical potential distribution in the packed bed electrode reactor during the deposition of $\operatorname{Ag}(\mathrm{I})$ ions. The lines represent the theoretical approach (Eq. (10)); a) 0.23, b) 0.47 , c) 0.59 , d) 0.70 and e) $0.94 \mathrm{~cm} \mathrm{~s}^{-1}$. The symbols are the values obtained experimentally. Working electrode: stainless steel-fibre of $81 \mathrm{~cm}^{-1}$ specific surface area. Potential of the electrolysis at $z=0: 0.1 \mathrm{~V} v s$. SHE. 


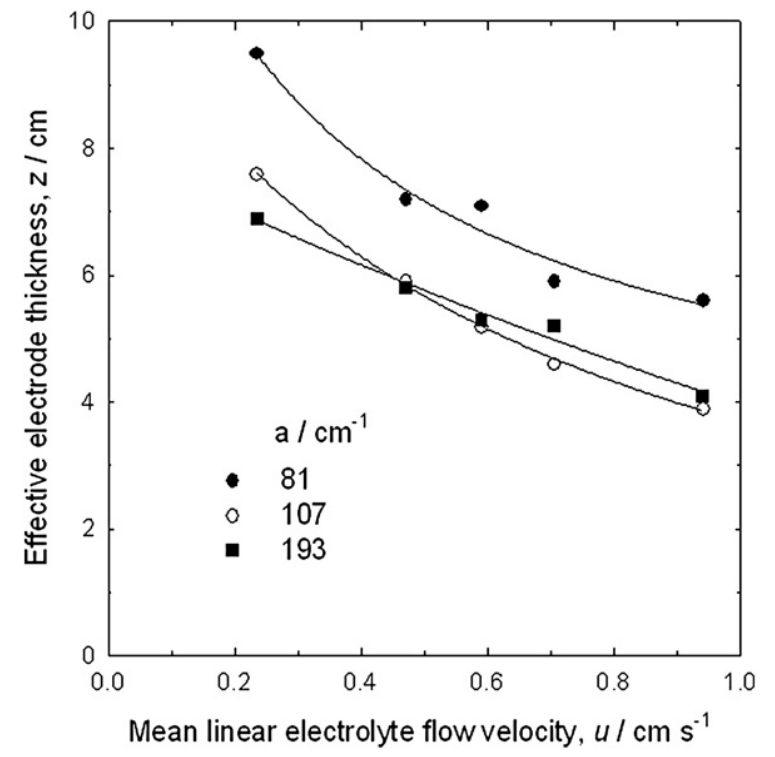

Fig. 5. Effective electrode thickness vs. mean linear flow velocity for the reduction of $\operatorname{Ag}(\mathrm{I})$ ions on three different specific surface area packed bed electrodes. The lines show the position on the electrode height, $z$, before hydrogen evolution starts, i.e. for potential drop $\varphi_{e}(z)-\varphi_{e}(z=0) \leq-0.400 \mathrm{~V}$. Working electrodes: stainlesssteel fibres.

the mass transport correlation is best evaluated through analysis of experimental data because it depends on the geometry of the electrode, type of fluid flow pattern, and the electrochemical reaction (Delanghe et al., 1990). In the following section the potential distribution curves are simulated using the $k_{m} a$ values from Fig. 3.

\subsection{Potential distribution in the packed bed electrode; determination} of the effective cathode thickness

The experimental measurements of the potential distribution were carried during the electrolysis of $\mathrm{Ag}(\mathrm{I})$ ions in the flow-through reactor in a single pass mode of operation (Fig. 1). The electrolysis were carried out by applying $0.1 \mathrm{~V} v s$. SHE on the current collector, at $z=0$, situated at the inlet of the packed bed electrode reactor. The maximum potential drop before hydrogen evolution starts, will be: $\varphi_{e}$ $(z)-\varphi_{e}(0)=-0.3-0.1=-0.4 \mathrm{~V}$. This allows a potential window of $0.4 \mathrm{~V}$ between the deposition of $\operatorname{Ag}(\mathrm{I})$ ions and the beginning of the hydrogen evolution reaction. This criterion, supported by current density vs. potential curves (Fig. 2), was previously proposed by Kreysa et al. (1971) to estimate the thickness of a porous electrode. The experimental potential distribution was compared to that obtained theoretically by using Eq. (3) and the data is shown in Tables 1 and 2.

Fig. 4 shows both, the experimental (symbols) and theoretical (lines) variation of the axial potential distribution with the position of the electrode $z$, at several mean linear velocities of the electrolyte, $\mathrm{u}$, for a $81 \mathrm{~cm}^{-1}$ specific surface area electrode. This Figure shows that there is a good agreement between the experimental and theoretical values over the length of the electrode. The potential becomes more negative as $\mathrm{z}$ increases due to the concentration decay of the electroactive species (Bennion and Newman, 1972; Fahidy, 1985; Newman and Tobias, 1962; Sioda, 1971).

The potential difference observed at a mean linear flow velocity of $0.23 \mathrm{~cm} \mathrm{~s}^{-1}$ (Fig. 4), shows that hydrogen evolution will occur only when $z>9.0 \mathrm{~cm}$ length, since $\left(\varphi_{e}(z)-\varphi_{\mathrm{e}}(z=0)\right)<-0.400 \mathrm{~V}$ at this length. At higher mean linear flow velocities, the curves indicate that hydrogen evolution will start at lower electrode lengths, as $\varphi_{e}(\mathrm{z})-\varphi_{e}(z=0)<$
$-0.400 \mathrm{~V}$. For example at mean linear flow velocities of $0.47,0.59,0.70280$ and $0.94 \mathrm{~cm} \mathrm{~s}^{-1}$ the evolution of hydrogen begins at $\mathrm{z}$ equal to $7.3,6.8,281$ 5.8 and $5.3 \mathrm{~cm}$, respectively. This is shown in Fig. 4 when the lines that 282 represent the potential intersect the horizontal line at $-0.4 \mathrm{~V} v s$. SHE that 283 defines the beginning of the hydrogen evolution reaction.

284

In order to show the maximum permissible length along the axial 285 axis of the electrode at which no hydrogen evolution occurs, i.e. where 286 $\varphi_{e}(z)-\varphi_{e}(z=0)=-0.400 \mathrm{~V}$, the electrode length $z$ was plotted $v s$. the 287 mean linear flow velocity $\mathrm{u}$, for the 81,107 and $193 \mathrm{~cm}^{-1}$ specific 288 surface area packed bed electrodes in Fig. 5. These data show the 289 effective electrode thickness before hydrogen evolution starts. In the 290 three cases, the maximum electrode length is shorter as the mean linear 291 flow velocity increases however, the maximum permissible length at 292 which no hydrogen evolution occurs is larger for the $81 \mathrm{~cm}^{-1}$ specific 293 surface area electrode at all velocities. The points of effective electrode 294 thickness for 107 and $193 \mathrm{~cm}^{-1}$ specific surface area at different mean 295 linear velocities behave similarly.

The larger permissible lengths obtained for the $81 \mathrm{~cm}^{-1}$ specific 297 surface area electrode are due to the fact that on this electrode the 298 concentration decay of the electroactive species is less rapid than on 299 electrodes with higher specific surface area. Nevertheless for design 300 purposes, the evolution of hydrogen should be avoided by adjustment 301 of the values of the mean linear flow velocity and the specific surface 302 area for a fixed electrode length.

The potential distribution results show the usefulness of this type of 304 analysis to estimate the optimum length of a packed bed electrode 305 reactor which allows efficient recovery of metals by avoiding hydrogen 306 evolution.

\section{Conclusions}

308

This work showed the use of potential distribution studies in 309 the design of a bed thickness of a flow-through porous electrode 310 during deposition of $\mathrm{Ag}(\mathrm{I})$ ions in $\mathrm{KNO}_{3}+\mathrm{NH}_{4} \mathrm{OH}$ aqueous 311 electrolyte. The comparison of both, experimental and theore- 312 tical potential distributions showed that flow rate and specific 313 surface area of the electrode determine the potential drop within 314 the packed bed cathode and therefore the effective thickness of 315 the porous bed electrode at which hydrogen evolution can be 316 avoided. The method used in this paper can be applied to other 317 electrically conductive flow-through porous electrode shapes to 318 establish the optimum electrode thickness.

\section{Uncited reference}

Walker and Wragg, 1977

\section{References}

Bennion, D.N., Newman, J., 1972. Electrochemical removal of copper ions from 323 very dilute solutions. J. Appl. Electrochem. 2, 113-122.

Delanghe, B., Tellier, S., Astruc, M., 1990. Mass transfer to a carbon or graphite 325 felt electrode. Electrochim. Acta 35, 1369-1376.

Doherty, T., Sunderland, J.G., Roberts, E.P.L., Pickett, D.J., 1996. An improved 327 model of potential and current distribution within a flow-through porous 328 electrode. Electrochim. Acta 41 (4), 519-526.

El-Deab, M.S., Saleh, M.M., El-Anoduli, B.E., Ateya, B.G., 1999. Electro- 330 chemical removal of lead ions from flowing electrolytes using packed bed 331 electrodes. J. Electrochem. Soc. 146 (1), 208-213. pp. 221-223. 
Gaunand, A., Hutin, D., Coeuret, F., 1977. Potential distribution in flow through porous electrodes under limiting current conditions. Electrochim. Acta 22 (1), 93-97.

Langlois, S., Coeuret, F., 1989. Flow-through and flow-by porous electrodes of nickel foam. II. Diffusion-convective mass transfer between the electrolyte and the foam. J. Appl. Electrochem. 19, 51-60.

Lanza, M.R.V., Bertazzoli, R., 2000. Renoval of Zn(II) from chloride médium using a porous electrode: current penetration withing the cathode. J. Appl. Electrochem. 30 (1), 61-70.

Like, S.E., Langer, S.H., 1991. Internal ohmic drop limits on effectiveness of packed bed electrodes obeying Tafel kinetics. J. Electrochem. Soc. 138, 2327-2330.

Matloz, M.J., Newman, J., 1986. Experimental investigation of a porous carbon electrode for the removal of mercury from contaminated brine. J. Electrochem. Soc. 133 (9), 1850-1859.

Newman, J., Tobias, C.W., 1962. Theoretical analysis of current distribution in porous electrodes. J. Electrochem. Soc. 109, 1183-1191.

Oropeza, M.T., González, I., Palomar, M., 1995. Patent No. 9101212, México.

Podlaha, E.J., Fenton, J.M., 1995. Characterization of a flow-by RVC electrode reactor for the removal of heavy metals from dilute solutions. J. Appl. Electrochem. 25, 299-306.

Ponce de León, C., Pletcher, D., 1996. The removal of $\mathrm{Pb}$ (II) from aqueous solutions using a reticulated vitreous carbon cathode cell - the influence of the electrolyte medium. Electrochim. Acta 41 (4), 533-541.

Sabacky, B.J., Evans, J.W., 1979. Eectrodeposition of metals in fluidized bed electrodes Part I. Mathematical model. J. Electrochem. Soc. 126, 1176-1180.

Saleh, M.M., 2004. On the effectiveness factor of flow-through porous electrode. J. Phys. Chem., B 108, 13419-13426.

Sioda, R.E., 1971. Distribution of potential in a porous electrode under conditions of flow electrolysis. Electrochim. Acta 16, 1569-1576.

Soltan, E.A., Nosier, S.A., Salem, A.Y., Mansour, I.A.S., Sedahmed, G.H., 2003. Mass transfer behaviour of a flow-by fixed bed electrochemical reactor under different hydrodynamic conditions. Chem. Eng. J. 91, 33-44.

Trainham, J.M., Newman, J., 1977. A flow through porous electrode model: application to metal ion removal from dilute streams. J. Electrochem. Soc. 124 (10), 1528-1540.

Walker, A.T.S., Wragg, A.A., 1977. The modelling of concentration-time relationships in recirculating electrochemical reactor systems. Electrochim. Acta 22, 1129-1134.

\section{List of symbols}

Symbol: Meaning

A: Specific surface area of the porous electrode (geometric area/volume of the electrode) $\left(\mathrm{cm}^{2} / \mathrm{cm}^{-3}\right)$

$B$ : Constant (Dimensionless)

$C$ : Constant (Dimensionless)
$C(z=0)$ : Concentration of electroactive species at the point of $z=0$ of the 389 porous electrode $\left(\mathrm{mol} \mathrm{cm}^{-3}\right) \quad 390$

$C(t)$ : Concentration of the electroactive species in the reservoir at any time, $t 391$ $\left(\mathrm{mol} \mathrm{cm}{ }^{-3}\right)$

$C(t=0)$ : Concentration of the electroactive species in the reservoir at time $t=0393$ $\left(\mathrm{mol} \mathrm{cm}{ }^{-3}\right)$

$d p$ : Particle size, shown in Table $1(\mathrm{~cm})$

E: Potential (V)

$k_{m}$ : Average mass transport coefficient $\left(\mathrm{cm} \mathrm{s}^{-1}\right)$

$F$ : Faraday constant, 96,485 $\left(\mathrm{C} \mathrm{mol}^{-1}\right)$

$J$ : Current density $\left(\mathrm{A} \mathrm{cm}^{-2}\right)$

$L$ : Electrode height, $9.5 \mathrm{~cm}$

$n$ : number of electrons transferred (dimensionless)

$Q$ : Volumetric flow rate $\left(\mathrm{cm}^{3} \mathrm{~s}^{-1}\right)$

$t$ : Time of electrolysis (s)

$u$ : Mean linear electrolyte velocity in empty channel $\left(\mathrm{cm} \mathrm{s}^{-1}\right)$

$V_{T}$ : Volume occupied by the electrolyte in the reservoir $\left(\mathrm{cm}^{3}\right)$

$z$ : Any arbitrary point along the porous electrode $(\mathrm{cm})$

Greek symbols

Symbol: Meaning

$\alpha$ : Parameter group, $\frac{k_{m} a(1-\varepsilon)}{u}\left(\mathrm{~cm}^{-1}\right)$

$\varepsilon$ : Electrode porosity (Dimensionless)

$(1-\varepsilon)$ : Fraction occupied by the porous electrode (Dimensionless)

$\varphi(z)$ : Potential difference at any position along the electrode (V)

$\varphi_{e}(z)$ : Electrolyte potential in an arbitrary position (V)

$\varphi_{e}(z=0)$ : Electrolyte potential at the packed electrode inlet (V)

$\varphi_{M}$ : Potential in the matrix of bed electrode $(\mathrm{V})$

$\sigma$ : Electrolyte conductivity $\left(\Omega^{-1} \mathrm{~cm}^{-1}\right)$

$\sigma_{e}:$ Interstitial conductivity, $\sigma_{e}=\sigma \frac{2 \varepsilon}{(3-\varepsilon)}\left(\Omega^{-1} \mathrm{~cm}^{-1}\right)^{1}$

$\tau_{T}$ : Residence time of the electrolyte in the reservoir, $\tau_{T}=\frac{V_{T}}{Q}(\mathrm{~s})$ $\omega$ : Angular velocity $\left(\mathrm{s}^{-1}\right)$ 